\title{
Bağcılıkta etkili sıcaklık toplamı hesaplamasında kullanılan farklı yöntemlerin karşılaştırılması
}

\section{Comparison of various methods of effective heat summation calculations in viticulture}

\author{
Burak AKTÜRK(i), Halil İbrahim UZUN(i) \\ Akdeniz Üniversitesi, Ziraat Fakültesi, Bahçe Bitkileri Bölümü, 07070, Antalya \\ Sorumlu yazar (Corresponding author): B. Aktürk, e-posta (e-mail): akturkbrk@gmail.com \\ Yazar(lar) e-posta (Author e-mail): uzun@akdeniz.edu.tr
}

\section{MAKALE BİLGİSI}

Alınış tarihi 11 Mart 2019

Düzeltilme tarihi 26 Mart 2020

Kabul tarihi 31 Mart 2020

\section{Anahtar Kelimeler:}

Vitis vinifera

Sicaklık

Ekoloji

Üzüm çeşidi

\section{ÖZ}

Antalya ekolojik koşullarında yetiştirilen 34 üzüm çeşidinin uyanma-olgunluk dönemine ait etkili sıcaklık toplamı (EST) istekleri değișik yöntemlerle belirlenmiștir. Her bir çeșit için saatlik, minimum, maksimum ve meteorolojik rasattaki sıcaklıkların esas alındığı 4 farklı günlük ortalama sıcaklık (GOS) değeri hesaplama yöntemine göre EST isteklerindeki değișim incelenmiștir. Bazı çeşitlerin EST istekleri farklı ekolojilerde elde edilen değerler ile karşlaştırılmıştır. Üzüm çeşitleri içerisinde en düşük EST isteği Early Sweet çeşidinde saptanmıștır. Bu çeşidin farklı GOS hesaplamaları için Winkler indisine göre saptanan EST isteği 912-954 derece gün (dg) arasında değişmiştir. Bu çeşidin farklı yöntemlere göre hesaplanan EST isteği ise en düşük $925 \mathrm{dg}$, en yüksek $983 \mathrm{dg}$ olarak saptanmıştır. Farklı GOS hesaplaması ve farklı yöntemlerin kullanılması çeşitlerin EST isteklerinde değişik düzeylerde farklılıklara yol açmıştır. Sonuç olarak GOS değerlerinin hesaplanmasında yöntemler arasındaki korelasyonun oldukça yakın olduğu, hesaplamalarda 24 saatlik ortalamanın alınmasının daha uygun olacağı fakat bunun temin edilemediği durumlarda diğer yöntemlerin kullanılmasının da çok önemli yanılgıya yol açmayacağı belirlenmiștir. Ayrıca, çeșitlerin EST isteklerinin saptanmasında, saatlik GOS değerleri kullanılarak Winkler indisi formülüne göre hesaplamanın daha uygun olacağı kararına varılmıştır.

\section{ARTICLE INFO}

Received 11 March 2019

Received in revised form 26 March 2020

Accepted 31 March 2020

\section{Keywords:}

Vitis vinifera

Heat summation

Ecology

Grape cultivar

\begin{abstract}
Effective heat summation requirements (EHS) of 34 grape cultivars for budburst-maturity period were determined by different methods in Antalya ecological conditions. The variations in EHS requirements of some cultivars were investigated by using four daily average temperature (DAT) calculation models by using hourly, minimum, maximum and meteorological observation temperature records. EHS requests of some varieties were compared with the values obtained in different ecologies. Among the grape cultivars, the lowest EHS request was determined in the Early Sweet cultivar. EHS requirements of this cultivar determined according to Winkler index ranged from 912 to 954 degree days (dd) for different daily average temperature calculation models. Meanwhile, The EHS requirement of Early Sweet ranged from 925 dd to 983 dd depending on calculation methods. Different DAT and EHS calculation models have led to differences in the EHS requirements of the varieties at different levels. As a result, it was determined that the correlation between the methods in calculating DAT values was very close, and it would be more convenient to take the 24-hour average in the calculations, but the use of other methods did not lead to an important error when DAT could not be provided. Furthermore, it was decided that it would be more appropriate using hourly DAT data in Winkler index for determining of EHS requirements of grape cultivars.
\end{abstract}




\section{Giriş}

Bağcılıkta olgunluk dönemi genelde 1-2 hafta gibi kısa bir süre içerisinde gerçekleşmektedir. Bu durum, özellikle büyük çaplı üretim yapan bağcllık işletmelerinde; pazar durumu, hasatta kullanilacak alet-ekipman ve malzemeler, hasatta kullanılacak işgücü, kültürel işlemler, üzümlerin depolanma durumu ve depoların hazırlığı gibi konularda planlamayı gerektirir. Dolayısıyla, hasat zamanının önceden doğru bir şekilde tahmin edilmesine ihtiyaç vardır. $\mathrm{Bu}$ açıdan yararlanılabilecek en önemli iki kriter; üzüm çeşitlerinin, uyanmadan olgunluğa kadar geçen gün sayıları ve ihtiyaç duydukları EST istekleridir (Jacob ve Winkler 1950).

Hava sıcaklıkları canlıların gelişimini etkileyen en önemli iklim faktörüdür. Genel olarak belirli bir dereceye kadar $11 \mathrm{k}$ sıcaklıklar gelişmeyi arttırırken, serin sıcaklıklar ise oransal olarak azaltır. Eşik sıcaklık; bitkinin gelişmeye başladığı sıcaklığı; optimum sıcaklık ise bitkinin en fazla geliştiği veya fotosentez yaptığı sicaklığı ifade eder. Sicaklık optimum derecenin üzerine çıktıkça gelişme oranı doğrusal olarak azalır. Eşik ve optimum sıcaklık değerleri canlı türlerine göre değişmektedir. Kışın yetişen bitkiler yazın yetişen bitkilere göre daha düşük eşik sıcaklık değerlerine sahiptir. Sicaklık, canlıların gelişme oranını gösteren en önemli göstergelerden biridir. EST, bitkilerin veya diğer canlıların olgunluk zamanının tahmin edilmesinde kullanılan ve hava sıcaklıklarının ölçülmesine dayanan en önemli hesaplama araçlarından biridir. Olgunluk zamanının tahmin edilmesi; işçi, makine ve parasal girdilerin düzenlenmesinin yanı sıra kültürel işlemlerle ilgili budama, gübreleme, sulama, ilaçlama gibi kültürel işlemlerin doğru zamanda yapılmasina ve bunlarla ilgili girdilerin uygun zamanda temin edilmesine yardımcı olur (Payero 2017).

Asmalar için gözlerin uyanmaya başladığı eşik sıcaklık değeri $10^{\circ} \mathrm{C}$ kabul edilir. Optimum sicaklıkların ise, yaprakların en fazla fotosentez yaptığ $25-35^{\circ} \mathrm{C}$ olduğu saptanmıştır (Mullins ve ark. 2004). Eşik sıcaklığın türlere, çeşitlere ve hatta büyüme safhası ve işlemine göre farklılık gösterebileceği bazı araştırıcılar tarafından ifade edilmiştir (McMaster ve Wilhelm 1997). Sicaklığın büyümeyi etkilemesinin temelinde, metabolik olaylarda rol alan enzimlerin aktivitelerinin belirli sicaklıklarda başlaması, artması ve yavaşlaması yatmaktadır (Bonhomme 2000). Son zamanlarda bu durumun enzimlerin oluşumunu tetikleyen genlerin çalışmaya başlamasıyla da yakından ilişkili olduğu belirlenmiştir (Ikegami ve ark. 2016). Üzüm çeşitlerinin EST istekleri, genellikle gözlerin uyanmasından olgunluğa (hasada) kadar geçen dönemdeki günlük ortalama hava sıcaklıkları ile eşik değerin arasındaki farkların toplanmasıyla elde edilir. Bunun amac1, bir ekolojide çeşitlerin hangi tarihlerde olgunlaşacağını önceden tahmin etmektir. Diğer taraftan bağ kuruluş aşamasında, ekolojilerin 1 Nisan-31 Ekim tarihleri arasındaki EST potansiyelleri hesaplanarak, o ekolojinin hangi çeşitlerin EST isteklerini karşılayabileceği belirlenebilir. Bir çeşidin belirli bir yöreye sıcaklık açısından uygun olabilmesi için; çeşidin EST isteğinin yörenin EST potansiyelinden daha düşük olması gerekmektedir. Böylece, bağ tesis aşamasında o yöre için sıcaklık açısından uygun çeşitler seçilir. Bu durumun, özellikle soğuk bölgelerde oldukça faydalı olacağı düşünülmektedir.

Gözlemlenen GOS değerlerinin hesaplanmasında, Winkler ve ark. (1974) tarafından günlük minimum (min) ve maksimum (max) değerlerin ortalamasının kullanılması önerilmiştir. Ancak gerçek anlamdaki GOS'u hesaplamak için, gün içinde saat başı yapılan rasatların ortalamasının alınması gerektiği belirtilmiştir
(Cross ve Zuber 1972; Perry ve ark. 1986; Yalçın ve ark. 2005). EST değerlerinin hesaplanmasında bazı araştırıcılar, eşik sıcaklığın altında kalan ve optimum sıcaklığın üstüne çıkan sıcaklıkların, toplamdan çıkarılmasını önermiştir (Perry ve ark. 1986; Fraisse ve Moraes 2018). Bu açıdan bağcılıkta GOS değerinin eşik sıcaklık altında kalması durumunda; Jacob ve Winkler (1950) tarafindan farkın genel toplamdan çıkarılması önerilmiş; ancak McMaster ve Wilhelm (1997) sıcaklıkların eşik sıcaklık altında kalması durumunda bunları eşik sıcaklık ile eşdeğer kabul etmiştir. Bağcılıkta EST değerlerinin hesaplanmasında optimum sıcaklık aralığının üst değeri olan $35^{\circ} \mathrm{C}$ 'nin üstündeki yüksek sıcaklıkların, EST'ye etkisi genelde yok sayılmıştır ve EST değeri hesaplamasında bu açıdan herhangi bir eksiltmeye gidilmemiştir (Jacob ve Winkler 1950). Bunun nedeni, genelde bağcılık yapılan yerlerin GOS değerinin, optimal sıcaklık aralığının üst değeri olan $35^{\circ} \mathrm{C}$ değerini pek aşmayan bölgelerde yapılıyor olmasından kaynaklanabilir. Yurdumuzun en sicak bölgelerinden olan Akdeniz ve Güney Doğu Anadolu gibi güney bölgelerde bile GOS değerleri nadiren $35^{\circ} \mathrm{C}$ üzerine çıkmaktadır. $\mathrm{Bu}$ bölgelerde günlük maksimum sıcaklıklar $40-45^{\circ} \mathrm{C}$ 'ye kadar çıssa bile, gece hava serinlediği için o güne ait ortalama sıcaklık değeri genelde $35^{\circ} \mathrm{C}$ 'nin altında kalmaktadır. $\mathrm{Bu}$ nedenle, yüksek sıcaklık stresinin EST'ye etkisi genellikle göz ardı edilmektedir. Benzer olarak asmalar uyandıktan sonra yurdumuzdaki bağcılık bölgelerinde GOS değerleri genelde eşik sıcaklık değerinin altına pek düşmemektedir. Bu nedenle yurdumuzda yapılan çalışmalarda GOS değerinin saptanmasında, eşik sicaklık $\left(10^{\circ} \mathrm{C}\right)$ altında kalan veya optimal üst sıcaklık $\left(35^{\circ} \mathrm{C}\right)$ değerinin üstüne çıkan sıcaklıklar, genellikle dikkate alınmamaktadır.

Üzüm çeşitlerinin uyanmadan olgunluğa kadar geçen gün sayıları, sıcak iklimden soğuk iklimlere ve iklimin yıllara göre değişimi bakımından oldukça farklı sonuçlar verebilmektedir. Örneğin uyanmadan olgunluğa kadar geçen gün sayısı; Cardinal üzüm çeşidi için sıcak iklime sahip Antalya koşullarında 102 gün olmasına karşın, diğer illerde 97-142 gün arasında değişmiştir. Benzer durum Trakya İlkeren çeşidi için yörelere göre 97-131 gün arasında, Yalova İncisi için 94-130 gün arasında ve Hamburg Misketi için 119-155 gün arasında değişmiştir (Çelik ve ark. 2005; Sağlam ve ark. 2009; Gazioğlu ve ark. 2009; Köse 2014; Kılıç ve ark. 2016).

Üzüm çeşitlerinin uyanmadan olgunluğa kadar geçen süredeki EST istekleri açısından, ekolojilere göre yapılan genel bir değerlendirmede; aynı çeşitte ekolojiler arasında ve hatta kendi ekolojisinde bile y1llara göre değişen farklılıklar ortaya çıkmıştır. Aynı ekolojide yıllara göre oluşan bu farklılıklar iklimsel değişikliklere bağlanır iken, ekolojiler arasındaki değişimler toprak ve iklim farklılıklarına ek olarak yetiştirme koşullarından (kültürel işlemler, anaç, terbiye sistemi, asmanın yaşı vb.), uyanma ve olgunlaşma zamanının değişik araştırıcılar tarafından farklı şekilde ölçülmesinden de kaynaklanabilmektedir. Örneğin Cardinal çeşidinin değişik y1llarda uyanma-olgunluk dönemindeki EST isteği; Antalya'da 1207 dg, Kalecik'de 1313 dg, Van'da 1095-1281 (420A anacina aş11) ve 1181-1317 (110R anacına aş111) dg, Tokat'ta 1221-1247 dg, Edirne'de 1267-1271 dg, Tekirdağ'da 1186-1258 dg olarak tespit edilmiştir. Bu durumda Cardinal çeşidinin EST isteğinde ekolojiler arasında \%9, aynı ekolojide ise \%0.3-16 arasında değişen farklılıklar ortaya çıkmıştır. EST isteği yukarıdaki ekolojilerde yetiştirilen Hamburg Misketi çeşidinde incelendiğinde; Van'da $1265 \mathrm{dg}$ ve Edirne'de $1701 \mathrm{dg}$ ile ekolojiler arası EST farkının \%34 e kadar çıktığı görülmektedir. Söz konusu çeşitte, aynı ekolojide yıllara göre EST fark1 ise 
\%10'a kadar çıkmıştır (Çelik ve ark. 2005; Sağlam ve ark. 2009; Gazioğlu ve ark. 2009; Köse 2014; Kılıç ve ark. 2016).

Aynı üzüm çeşidinin EST isteğinin saptanmasında değişik araştırıcılar tarafından farklı sonuçlar elde edilmesinin ana nedenlerinde biri de, hesaplama yöntemi ile sıcaklık kayıtlarının alınma yeri ve şeklinden kaynaklanan farklılıklardır. Genel olarak günlük ortalama sıcaklık değerlerinin hesaplanmasında Winkler ve ark. (1974), tarafindan min ve max sicaklıklar esas alınmıştır. Bazı araştırıcılar aylık sıcaklık ortalamasını o ay için gerekli gün sayısı ile çarparak hesaplamışlardır (Gazioğlu ve ark. 2009). Ayrıca bazı çalışmalarda hava sıcaklığı kayıtları, denemenin yapıldığ 1 bağdan belirli uzaklıkta olan meteoroloji istasyonlarından alınmıştır (Kılıç ve ark. 2016; Gazioğlu ve ark. 2009; Sağlam ve ark. 2009). Sicaklık değerinin günlük alınma sayısı ve şekli de EST değerlerini etkileyebilmektedir. Meteoroloji istasyonlarından alınan eski günlük ortalama sıcaklık değerleri, genelde o gün içerisinde belirli saatlerde yapılan 3 rasadın (saat $07.00,14.00$ ve 21.00) kullanılması ile oluşturulan bir formülle hesaplanması şeklindedir. Ancak son y1llarda bazı istasyonlarda dijital olarak saatlik rasat yapılmakta, o güne ait ortalama sicaklık yapılan saatlik tüm rasatlar kullanılarak hesaplanmaktadır. $\mathrm{Bu}$ açıdan, deneme yapılan araziye yerleştirilen dijital sıcaklık kaydedici cihazlarla, saatlik olarak yapılacak kayıtlar en pratik ve gerçekçi ölçüm yöntemi olduğu bulunmuştur (Cross ve Zuber 1972; Gu 2016).

$\mathrm{Bu}$ çalışmanın amacı; üzüm çeşitlerinin EST isteklerinin saptanmasında kullanılan farklı GOS hesaplama modellerinin ve her bir çeşidin uyanma- olgunluk dönemindeki EST isteklerinin belirlenmesinde kullanılan farklı hesaplama yöntemlerinin karşılaştırmasını yapmaktır.

\section{Materyal ve Yöntem}

\subsection{Materyal}

Deneme, Antalya'da Akdeniz Üniversitesi Ziraat Fakültesi bağlarında yer alan 34 adet sofralık üzüm çeşidinde 2017 y1lında yürütülmüştür. Araştırmanın yürütüldüğü bağların denizden yüksekliği $50 \mathrm{~m}$ ve denize uzaklığı ise yaklaşı 5 km'dir. Tüm bağ, kırmızı toprak (terra-rossa) grubuna sahip arazi üzerindedir. Çeşitler 99R anacı üzerinde veya kendi kökleri üzerinde yetiştirilmiştir. Hesaplamalarda EST değerlerine az miktarda etki edebilecek olan bitki yaşı, anaç, terbiye sistemi gibi faktörler göz ardı edilmiştir. Günlük ortalama sicaklıklar, bağ içerisinde asma seviyesindeki rasat siperine yerleştirilen dijital bir sıcaklık ve nem kaydedici cihaz (Extech 42270) yardımıyla saatlik olarak alınan değerlerden hesaplanmıştır.

\subsection{Yöntem}

\subsubsection{GOS hesaplama yöntemleri}

Gerçek anlamdaki GOS değerleri gün içinde saat başı yapılan rasatların aritmetik ortalamasıdır (Yalçın ve ark. 2005). GOS saptanmasında çalışmanın yürütüldüğü araziye yerleştirilen ve kayıt cihazı tarafından saat başı yapılan rasatlardan faydalanılmıştır. $\mathrm{Bu}$ amaçla her saat başında bir rasat olacak şekilde, bir gün için toplam 24 hava sıcaklığ rasadının aritmetik ortalaması, GOS değeri olarak alınmıştır. Bağcılıkta günlük EST hesaplamalarında genel olarak Winkler indisi denilen aşağıdaki formül kullanılır ve birimi derece gün olarak ifade edilir (Winkler ve ark. 1974).
EST ( $\left.\mathrm{T}_{\text {ortalama- }} \mathrm{T}_{\text {eşik }}\right)$

Tortalama: Günlük ortalama sıcaklık $\left({ }^{\circ} \mathrm{C}\right)$

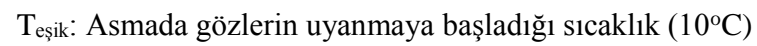

EST hesaplamasında her bir çeşide ait uyanma-olgunluk dönemindeki her bir güne ait günlük EST istekleri hesaplanmıștır. Jacob ve Winkler (1950) tarafindan bildirildiği gibi GOS değeri eşik sıcaklığın altına düşmesi durumunda oluşan negatif değerler, genel ortalamadan çıkarılmıştır. GOS hesaplama yöntemlerinin Winkler indisinde belirtilen GOS değerinde kullanılan farklı hesaplama yöntemlerinin EST değerindeki değişime etkisini incelemek amacıyla, dört farklı GOS hesaplama yöntemi kullanılmıştır. Günlük saat baş1 yapılan sıcaklık ölçümlerin ortalamasına ek olarak, Birgücü ve Karsavuran (2009) tarafından belirtilen aşağıdaki 3 farklı yöntemle hesaplanan GOS verilerinin, Winkler indisine uyarlanması sonucu elde edilen değerler saptanmıştır.

$$
\mathrm{GOS}=\left\{\begin{array}{l}
\frac{\mathrm{T}_{\max }+\mathrm{T}_{\min },}{2}, \\
\frac{\mathrm{T}_{\max }+2 \mathrm{~T}_{\min },}{3}, \\
\frac{\mathrm{T}_{07^{00}}+\mathrm{T}_{14^{00}}+\left(2 \times \mathrm{T}_{20^{00}}\right)}{4},
\end{array}\right.
$$

$T_{\max }$ : Günlük maksimum sicaklık değeri, $\mathrm{T}_{\min }$ : Günlük minimum sıcaklık değeri $, \mathrm{T}_{07}{ }^{00}, \mathrm{~T}_{14}{ }^{00} \mathrm{~T}_{21}{ }^{00}$ : sırasıyla günlük $07.00,14.00$ ve 21.00 saatlerinde yapılan sıcaklık ölçüm değerleri.

\subsubsection{EST hesaplama yöntemleri}

Farklı EST hesaplama yöntemlerinin çeşitlerin EST değerini ne derece değișikliğe yol açtığını belirlemek amacıyla her bir çeşit için uyanma-olgunluk dönemindeki EST istekleri, Winkler indisindeki (Winkler ve ark. 1974) saatlik GOS ortalamasıyla bulunan EST isteğine ek olarak, McMaster ve Wilhelm (1997) ile Nunes ve ark. (2016) tarafindan bildirilen aşağıdaki yöntemlerle de hesaplanmıştır:

McMaster ve Wilhelm (1997) yöntemi;

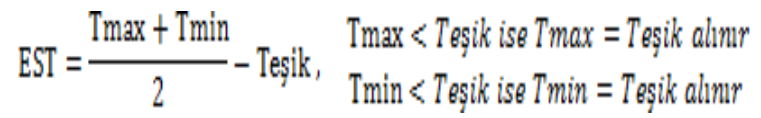

Nunes ve ark. (2016) yöntemi;

$$
\begin{aligned}
& T \min >\mathrm{T} \text { eşik ise, EST }=\frac{(T \min -T \text { eşik })+(T \max -T \text { eşik })}{2} \\
& T \max <T \text { eşik ise, EST }=0
\end{aligned}
$$

Her bir çeşit için uyanma-olgunluk döneminde farklı yöntemlerle yapılan hesaplamalar sonucu elde edilen GOS değerleri, Minitab ${ }^{\circledR} 16$ istatistik paket programı ile korelasyon analizine tabi tutulmuştur. 


\section{Bulgular ve Tartışma}

Farklı yöntemlerle tespit edilen GOS değerleri arasındaki korelasyon katsayıları 0.991-0.997 arasında değişmiştir (Çizelge 1). Bu çizelgedeki korelasyon katsayıları incelendiğinde tüm yöntemlerin, 24 saatlik rasat ile saptanan GOS değerleri ile çok yakın bir ilişkide olduğu görülmüş̧ür. En yüksek ilişkinin ise, 07.00-14.00-21.00 saatlerinde yapılan rasatları kullanan yöntemle 24 saat ortalaması arasında olduğu görülmüştür.

Çizelge 1. Farklı GOS hesaplama yöntemlerin korelasyon katsayıları. Table 1. Correlation coefficient of different DAT methods.

\begin{tabular}{cccc}
\hline \multirow{2}{*}{$\begin{array}{c}\text { GOS hesaplama } \\
\text { yöntemleri }\end{array}$} & \multicolumn{3}{c}{ GOS hesaplama yöntemleri } \\
\cline { 2 - 4 } & $\begin{array}{c}\text { 24 saat } \\
\text { ortalama }\end{array}$ & $(\mathbf{m a x}+\mathbf{m i n}) / \mathbf{2}$ & $(\mathbf{m a x}+\mathbf{2 m i n}) / \mathbf{3}$ \\
\hline $\mathbf{M a x + m i n ) / 2}$ & 0.995 & - & - \\
$(\mathbf{M a x}+\mathbf{2 m i n}) / \mathbf{3}$ & 0.991 & 0.996 & - \\
$\mathbf{( 7 + 1 4 + 2 \times 2 1 ) / 4}$ & 0.997 & 0.990 & 0.986 \\
\hline
\end{tabular}

Araştırma süresince ilk uyanan çeşitten (01.03.2017), son hasada kadar geçen dönemde (21.08.2017) gözlenen en düşük ve en yüksek ortalama sicaklık değerleri sirasıyla $9.95^{\circ} \mathrm{C}$ ve $36.96^{\circ} \mathrm{C}$ olarak ölçülmüştür. Gün içerisinde maksimum hava sıcaklığının değişik günlerde ve bazı saatlerde $40^{\circ} \mathrm{C}$ üzerinde olduğu (en yüksek: $46.5^{\circ} \mathrm{C}$ ) kayitlar da tespit edilmiştir. Çalışmanın yürütüldüğü bağın bulunduğu yöreye ait EST potansiyeli $3359.58 \mathrm{dg}$ olarak (1 Nisan-31 Ekim) tespit edilmiştir. Buna göre, bir yörenin iklim özelliğinin EST değerine göre sınıflandırıldığında, bağın bulunduğu Antalya merkez ilçe 'sıcak' iklim kuşağında yer almıştır (Çelik ve ark. 1998; Winkler ve ark. 1974).

Farklı GOS hesaplama yöntemlerine göre Winkler indisi esas alınarak hesaplanan çeşitlere ait EST istekleri Çizelge 2'de verilmiştir. Buradan görüldüğü şekilde çeşitlerin en düşük EST isteği değeri daima $\max +2 \mathrm{~min} / 3$ formülünden elde edilmiştir. Buna karş1lk, $\max +\min / 2$ formülü, diğer GOS hesaplama yöntemlerine göre her bir çeşit için daima en yüksek EST değerini oluşturmuş̧ur.

Çizelge 2. Farklı GOS hesaplama yöntemlerine göre EST değerlerinin değişimi.

Table 2. Variation in EHS values calculated by different DAT methods.

\begin{tabular}{|c|c|c|c|c|}
\hline \multirow{3}{*}{ Çeşitler } & \multicolumn{4}{|c|}{ EST isteği (dg) } \\
\hline & \multirow{2}{*}{24 Saat ortalamas 1} & $\mathrm{~T}_{\max }+\mathrm{T}_{\min }$ & $T_{\max }+2 T_{\min }$ & $\mathrm{T}_{07}{ }^{00}+\mathrm{T}_{14}{ }^{00}+\left(2 \mathrm{XT}_{21}{ }^{00}\right)$ \\
\hline & & 2 & 3 & 4 \\
\hline Alphonse Lavallee & 1585.48 & 1569.22 & 1313.85 & 1545.87 \\
\hline Amasya Beyazı & 1583.38 & 1604.90 & 1327.27 & 1573.60 \\
\hline Atasarısı & 1473.84 & 1489.05 & 1244.43 & 1466.80 \\
\hline Autumn Royalle & 1974.33 & 1993.65 & 1684.70 & 1965.65 \\
\hline Black Magic & 1352.10 & 1363.89 & 1079.23 & 1338.78 \\
\hline Cardinal & 1207.20 & 1220.05 & 1009.50 & 1202.63 \\
\hline Çavuş & 1684.46 & 1706.35 & 1416.57 & 1673.43 \\
\hline Çınarlı Karası & 1768.93 & 1782.00 & 1504.13 & 1758.65 \\
\hline Early Sweet & 925.48 & 954.24 & 721.34 & 912.52 \\
\hline Flame Seedless & 1381.13 & 1406.60 & 1154.60 & 1378.93 \\
\hline Hafizali & 1546.63 & 1570.10 & 1292.43 & 1537.80 \\
\hline Hamburg Misketi & 1428.43 & 1449.00 & 1188.93 & 1420.23 \\
\hline İtalia & 1657.80 & 1670.75 & 1408.87 & 1647.50 \\
\hline $\mathrm{K}-7$ & 1714.63 & 1712.95 & 1428.17 & 1685.63 \\
\hline Kabarcık & 1911.83 & 1935.35 & 1615.40 & 1899.33 \\
\hline Kara Erik & 2114.55 & 2136.05 & 1800.60 & 2098.98 \\
\hline Kozak Beyazı & 1496.03 & 1513.80 & 1256.60 & 1489.58 \\
\hline Kozak Siyahı & 1744.28 & 1759.80 & 1477.57 & 1735.83 \\
\hline Michelle Palieri & 1791.13 & 1806.75 & 1516.30 & 1781.43 \\
\hline Muscat Bleu & 1568.93 & 1589.80 & 1308.83 & 1556.05 \\
\hline Muscat Reine des Vignes & 1461.91 & 1487.30 & 1215.13 & 1450.98 \\
\hline Perlette & 1451.91 & 1477.70 & 1209.77 & 1445.28 \\
\hline Prima & 1197.60 & 1230.75 & 1020.77 & 1212.60 \\
\hline Reçel Üzümü & 2127.22 & 2142.35 & 1824.23 & 2111.83 \\
\hline Red Globe & 1810.31 & 1822.10 & 1537.33 & 1796.88 \\
\hline Regent & 1509.81 & 1533.50 & 1258.17 & 1499.70 \\
\hline Sultani Çekirdeksiz & 1803.29 & 1821.95 & 1518.33 & 1789.48 \\
\hline Superior Seedless & 1307.00 & 1334.00 & 1083.90 & 1301.70 \\
\hline Thompson Seedless & 1605.30 & 1628.45 & 1346.13 & 1597.00 \\
\hline Trakya İlkeren & 1174.67 & 1187.30 & 978.57 & 1169.80 \\
\hline Uslu & 1149.68 & 1172.15 & 953.40 & 1151.40 \\
\hline Verigo & 1662.71 & 1677.60 & 1414.60 & 1653.83 \\
\hline Victoria & 1282.66 & 1313.20 & 1068.20 & 1280.43 \\
\hline Yalova İncisi & 1261.70 & 1284.75 & 1059.07 & 1260.28 \\
\hline
\end{tabular}


Araştırma kapsamında Winkler indisi dışında, McMaster ve Wilhelm (1997) ile Nunes ve ark. (2016) gibi bazı araştırıcılar tarafindan belirtilen, farklı hesaplama yöntemleri kullanılarak da çeşitlerin EST istekleri hesaplanmıştır (Çizelge 3). Farklı yöntemlerle her bir çeşit için saptanan EST isteklerinin genel olarak birbirine yakın olmakla beraber, bu yöntemlerle elde edilen değerlerin büyükten küçüğe doğru; McMaster ve Wilhelm (1997) > Nunes ve ark. (2016) > Winkler ve ark. (1974) seklinde bir sıralamaya sahip olduğu görülmüştür. Aradaki bu farklılıkların nedeni ise her bir yöntemin farklı GOS değeri hesaplama prensipleri üzerine kurulmuş olmasıdır. Bu durum McMaster ve Wilhelm (1997) tarafindan yapılan çalışmanın sonuçlarıyla da desteklenmektedir. Araştırıcılar farklı prensipler doğrultusunda çalışan aynı derece gün saptama formülünü 1987 yılına ait bir veri setine uyguladıklarında, bir ay için hesaplanan derece gün değerlerinin \%80'e varan derecede farklılıklara neden olduğunu göstermişlerdir. $\mathrm{Bu}$ farklılıkların yaz aylarında çok az olduğunu tespit eden araştırıcılar, bahar aylarında yüksek seviyelere çıkan farklardan söz etmektedirler. $\mathrm{Bu}$ durum, çalışmanın Antalya gibi sıcak ve buna ek olarak gece ile gündüz arasındaki sıcaklık farklılıklarının az olduğu bir yerde yapılmış olması, yöntemler arasındaki korelasyon katsayılarının yüksek ve birbirine yakın çıkmasına yol açmış olabileceğini akla getirmektedir. Bu nedenle yöntemlerin daha soğuk iklime sahip bağ alanlarında da test edilmesinde yarar vardır.

Ayrıca, Winkler indisinin temel parametrelerinden biri olan, GOS değerinin tespitinde de farklı yöntemlerin söz konusu olduğu Birgücü ve Karsavuran (2009) tarafindan bildirilmiştir. Meteoroloji Genel Müdürlüğü ile yapılan yazılı görüşmeler sonucunda edinilen bilgiye göre, 1926-2010 yılları arasındaki GOS hesaplar1: 07.00-14.00-21.00 (rasat istasyonunun bulunduğu konumun yerel saatine göre) saatlerinde yapılan rasatlar sonucunda kaydedilen sıcaklık değerleri ile GOS hesaplaması seklinde yapıldığı öğrenilmiştir. 2017 yılının Ocak ayından itibaren ise tüm Türkiye'de otomatik meteoroloji sistemleri üzerinden, saat başı alınan rasatların (24 değer) aritmetik ortalaması alınarak yapıldığı bilgisi edinilmiştir. Bu nedenle, sıcaklık rasatlarının dışarıdan temin edilmek zorunda olduğu durumlarda, Meteoroloji Bölge Müdürlükleri'nden alınacak 2006 yılı öncesine ait kayıtların da gerçek değerler yerine kullanılabilecek nitelikte olduğu kararına varılmıştır. Ayrıca minimum-maksimum termometreler kullanılarak, üretimin planlandığı arazide, alınacak günlük rasatların da ortalama sıcaklık tespiti için yeterli olacağı düşünülmektedir.

Çizelge 3. Üzüm çeşitlerinin EST isteklerinin hesaplama yöntemine göre değişimi.

Table 3. EHS requirements of grape cultivars depending on methods.

\begin{tabular}{|c|c|c|c|}
\hline Çeşitler & Winkler ve ark.(1974) & Nunes ve ark yöntemi (2016) & McMaster ve Wilhelm yöntemi (1997) \\
\hline Alphonse Lavallée & 1585.48 & 1586.21 & 1592.85 \\
\hline Amasya Beyazı & 1583.38 & 1594.76 & 1615.15 \\
\hline Atasarıs1 & 1473.84 & 1476.41 & 1484.55 \\
\hline Autumn Royalle & 1974.33 & 1979.58 & 1992.95 \\
\hline Black Magic & 1352.10 & 1354.01 & 1362.95 \\
\hline Cardinal & 1207.20 & 1208.76 & 1216.90 \\
\hline Çavuş & 1684.46 & 1695.59 & 1717.55 \\
\hline Çınarlı Karası & 1768.93 & 1769.16 & 1777.30 \\
\hline Early Sweet & 925.48 & 952.06 & 982.74 \\
\hline Flame Seedless & 1381.13 & 1392.08 & 1409.60 \\
\hline Hafizali & 1546.63 & 1560.29 & 1583.20 \\
\hline Hamburg Misketi & 1428.43 & 1441.44 & 1461.30 \\
\hline İtalia & 1657.80 & 1659.88 & 1665.45 \\
\hline $\mathrm{K}-7$ & 1714.63 & 1701.53 & 1719.05 \\
\hline Kabarcık & 1911.83 & 1926.54 & 1949.45 \\
\hline Kara Erik & 2114.55 & 2127.51 & 2147.90 \\
\hline Kozak Beyazı & 1496.03 & 1500.98 & 1514.35 \\
\hline Kozak Siyahı & 1744.28 & 1745.74 & 1756.25 \\
\hline Michelle Palieri & 1791.13 & 1793.73 & 1807.10 \\
\hline Muscat Bleu & 1568.93 & 1584.18 & 1607.35 \\
\hline Muscat Reine des Vignes & 1461.91 & 1479.70 & 1503.10 \\
\hline Perlette & 1451.91 & 1467.09 & 1490.00 \\
\hline Prima & 1197.60 & 1216.93 & 1222.50 \\
\hline Reçel Üzümü & 2127.22 & 2131.27 & 2141.50 \\
\hline Red Globe & 1810.31 & 1812.11 & 1821.05 \\
\hline Regent & 1509.81 & 1524.13 & 1544.50 \\
\hline Sultani Çekirdeksiz & 1803.29 & 1813.06 & 1833.45 \\
\hline Superior Seedless & 1307.00 & 1322.99 & 1345.90 \\
\hline Thompson Seedless & 1605.30 & 1617.14 & 1639.10 \\
\hline Trakya İlkeren & 1174.67 & 1176.96 & 1185.90 \\
\hline Uslu & 1149.68 & 1157.14 & 1173.50 \\
\hline Verigo & 1662.71 & 1664.11 & 1670.75 \\
\hline Victoria & 1282.66 & 1293.74 & 1315.70 \\
\hline
\end{tabular}


Farklı üzüm çeşitlerinin yurdumuzdaki sıcak iklimden soğuk iklime kadar değişen farklı yörelerde uyanma-olgunlaşma dönemindeki EST istekleri ve gün sayıları birçok araştırıcı tarafından incelenmiştir. Diğer araştırıcılar tarafından saptanan, sıcak ve soğuk iklimde yer alan değişik bölgelerde yer alan bazı yörelerde yetiştirilen üzüm çeşitlerin uyanma-olgunluk dönemindeki EST istekleri ve gün sayılarına ait veriler Çizelge 4'de özetlenmiştir. Buradaki EST değerleri; Antalya için Uzun (1997) ile Aktürk ve Uzun (2019), Kalecik/Ankara için Çelik ve ark. (2005), Van için Gazioğlu ve ark. (2009), Tekirdağ için Sağlam ve ark. (2009), Samsun için Köse (2014), Tokat için Kılıç ve ark. (2016) tarafından saptanmıştır.

Çeşitlerin incelenmesinden görüldüğü şekilde Antalya ekolojisinde olduğu gibi yıllar arasında Trakya İlkeren (T. İlkeren)'de $87 \mathrm{dg}$, Alphonse Lavallee (A. Lavallee)' de 70 dg'lik fark oluşmuştur. $\mathrm{Bu}$ durum, o yöredeki yıllık iklim değişikliklerine bağlanabilir. Diğer taraftan Ankara ve Antalya'da yetiştirilen A. Lavallee çeşidinde ekolojiler arasında 19 dg gibi oldukça küçük fark saptanmıştır. Buna karşın, Antalya ve Edirne'de yetiştirilen Hafizali çeşidinde olduğu gibi bu farkın 165 dg gibi oldukça yüksek rakamlar çıktığı da görülmüştür. Gün sayısı açısından çeşitler ekolojilere göre karşılaştırıldığında aradaki farklar; Tekirdağ ve Tokat ekolojilerinde yetiştirilen Cardinal çeşidinde olduğu gibi 0 güne düşmekte, fakat Antalya ve Samsun'da yetiştirilen T. İlkeren'de olduğu gibi 34 güne kadar çıkabilmektedir. Değişik yayınlarda görülen herhangi bir çeşidin EST isteğindeki farklı rakamların, ekolojilerin iklim ve topraklarındaki farklılıkların yanı sıra; anaçlardaki, bitki yaşlarındaki, yetiştirme koşullarındaki ve araştırıcıların hesaplama yöntemlerindeki farklılıklardan da kaynaklanabileceğini de gözden uzak tutmamak gerekir.

\section{Sonuç ve Öneriler}

Yukarıda belirtilen tüm farklı sıcaklık ölçüm yöntemleri ve günlük ortalama hava sıcaklığı hesaplama yöntemleri, üzüm çeşitlerinin gerçek EST isteklerinin saptanmasını ve karşılaştırılmasını zora sokmaktadır. Çeşidin gerçek EST değerinin saptanabilmesi için, o çeşidin uyanma ve olgunluk tarihleri arasında kalan dönemde her bir gün için etkili sıcaklık değerinin hesaplanması gerekir. $\mathrm{Bu}$ amaçla yapılacak günlük ortalama hava sıcaklıklarının hesaplamasının da, bağ içine yerleştirilen veri kaydedici cihazlardan alınan değerlerle yapılmasının daha doğru olacağı sonucuna varılmıştır.

EST hesaplamalarında kullanılacak GOS değerleri gerçeğe en yakın olarak saatlik rasatlarla elde edilebileceği kanaatine varılmıştır. Ancak, GOS hesaplamasında kullanılan yöntemler arasındaki korelasyon katsayıları oldukça yüksek çıkmıştır. Bu nedenle, saatlik rasadın yapılamadığı yerlerde diğer hesaplama yöntemlerini de kullanmak fazla yanıltıcı olmayacaktır. Fakat bu çalışma, Antalya gibi nispeten sıcak olan ve ayrıca gece ile gündüz arasındaki sicaklık farklılıklarının da az olduğu bir yerde yapılmıştır. Bu nedenle, söz konusu formüllerin yapay sıcaklık veri setleriyle veya gece ile gündüz sıcaklık farklarının daha yüksek olduğu daha serin iklim kuşaklarında ve birkaç y1l ardışı olarak test edilmesinde yarar vardır. EST hesaplamalarında aylık sıcaklık ortalamalarından çok, o dönemdeki her bir güne ait GOS değerlerinin hesaplamada kullanılması daha gerçekçi sonuçlara ulaşılmasını sağlayacaktır. Bundan sonra yapılacak olan EST hesaplamaları içeren çalışmalarda, araştırıcıların kullandıkları yöntem ile verileri elde etme şekillerini, açı ve ayrıntılı olarak belirtmesi gerekmektedir. Böylece, bu konuda yapılacak çalışmaların kendi aralarındaki karşılaştırılmalarda oluşabilecek karışıklıklar da önlenmiş olacaktır.

Çizelge 4. Değişik ekolojilerde yetişen aynı üzüm çeşitlerinin EST istekleri.

Table 4. EHS requirements of same grape cultivars grown in different ecologies.

\begin{tabular}{|c|c|c|c|c|c|c|c|c|c|c|c|c|c|}
\hline \multirow{4}{*}{ Çeşitler } & \multicolumn{13}{|c|}{ Bağ ekolojileri } \\
\hline & \multicolumn{3}{|c|}{ Antalya } & \multirow{2}{*}{\multicolumn{2}{|c|}{ Kalecik/Ankara }} & \multirow{2}{*}{\multicolumn{2}{|c|}{ Samsun }} & \multirow{2}{*}{\multicolumn{2}{|c|}{ Tekirdağ }} & \multirow{2}{*}{\multicolumn{2}{|c|}{ Tokat }} & \multirow{2}{*}{\multicolumn{2}{|c|}{ Van }} \\
\hline & \multicolumn{2}{|c|}{2017} & \multirow{2}{*}{$\begin{array}{l}1997 \\
\text { EST }\end{array}$} & & & & & & & & & & \\
\hline & EST & Gün & & EST & Gün & EST & Gün & EST & Gün & EST & Gün & EST & Gün \\
\hline $\begin{array}{l}\text { Alphonse } \\
\text { Lavallee }\end{array}$ & 1585 & 120 & 1655 & 1604 & 133 & --- & -- & --- & --- & --- & --- & --- & --- \\
\hline Cardinal & --- & --- & 1397 & 1313 & 112 & 1455 & 142 & 1293 & 122 & 1221 & 122 & 1228 & 115 \\
\hline $\begin{array}{l}\text { Trakya } \\
\text { İlkeren }\end{array}$ & 1175 & 101 & 1088 & 1073 & 97 & 1210 & 131 & 1050 & 110 & 1052 & 117 & --- & --- \\
\hline $\begin{array}{l}\text { Michelle } \\
\text { Palieri }\end{array}$ & 1791 & 135 & --- & --- & --- & --- & --- & 1715 & 145 & --- & --- & --- & --- \\
\hline Victoria & 1283 & 116 & --- & --- & --- & --- & --- & --- & --- & 1273 & 135 & --- & --- \\
\hline Çavuş & 1684 & 136 & --- & 1410 & 125 & 1420 & 142 & --- & --- & --- & --- & --- & --- \\
\hline Y.İncisi & 1261 & 107 & --- & 1234 & 114 & 1239 & 123 & 1172 & 112 & --- & --- & 1187 & 114 \\
\hline Hafizali & 1547 & 130 & --- & 1667 & 142 & --- & --- & 1823 & 147 & --- & --- & --- & --- \\
\hline
\end{tabular}

\section{Teşekkürr}

Bu çalışmayı Yüksek Lisans Tezi olarak FYL-2017-2696 nolu proje ile destekleyen Akdeniz Üniversitesi Bilimsel Araştırma Projeleri Koordinasyon Birimi'ne teşekkür ederiz.

\section{Kaynaklar}

Aktürk B, Uzun Hİ (2019) Bazı sofralık üzüm çeşitlerinin Antalya'daki değişik yörelere uygunlukları ve etkili sıcaklık toplamı istekleri. Mediterranean Agricultural Sciences 32(3): 267-273.
Birgücü AK, Karsavuran Y (2009) Gün-derece modellemeleri ve bitki korumada kullanım olanakları. Anadolu Dergisi 19(2): 98-117.

Bonhomme R (2000) Bases and limits to 'degree.day' units. European Journal of Agronomy 13: 1-10.

Cross HZ, Zuber MS (1972) Prediction of flowering dates in maize based on different methods of estimating thermal units. Agronomy Journal 64: 351-355.

Çelik H, Ağaoğlu YS, Fidan Y, Marasalı B, Söylemezoğlu B (1998) Genel bağcıllk. Sunfidan A.Ş. Mesleki Kitaplar Serisi: 1, Ankara.

Çelik H, Söylemezoğlu G, Çetiner H, Kunter B, Çakır A (2005) Bazı üzüm çeşitlerinin Kalecik (Ankara) koşullarındaki fenolojik 
özellikleri ile etkili sıcaklık toplamı (EST) isteklerinin belirlenmesi. Türkiye 6. Bağcılık Sempozyumu Cilt 2, Tekirdağ, s. 390-397.

Fraisse CW, Moraes SVP (2018) Degree-days: growing, heating, and cooling. IFAS extension, University of Florida, ABE 381.

Gazioğlu ŞRİ, Balta F, Cangi R (2009) Bazı sofralık üzüm çeșitlerinin Van ekolojik koşullarındaki etkili sıcaklık toplamı değerlerinin belirlenmesi. Harran Üniversitesi Ziraat Fakültesi Dergisi 13(3): 49-59.

Gu S (2016) Growing degree hours - a simple, accurate, and precise protocol to approximate growing heat summation for grapevines. International Journal of Biometeorology 60: 1123-1134.

Ikegami AK, Sakamoto T, Shiboya K, Katayama T, Takai MG (2016) Effects of abscisic acid treatment on berry coloration and expression of flavonoid biosynthesis genes in grape. American Journal of Plant Sciences 7: 1325-1336.

Jacob HE, Winkler AJ (1950) Grape growing in California. Circular 116. California Agricultural Extension Service, College of Agriculture, University of California, Berkeley, California.

Kılıç D, Topal H, Kaya Y, Başaran B, Yağcı A, Cangi R (2016) Bazı erkenci üzüm çeşitlerinin Tokat merkez koşullarına adaptasyonu (1). VII. Ulusal Bahçe Bitkileri Kongresi, Çanakkale, 2: 678-682.

Köse B (2014) Phenology and ripening of Vitis vinifera L. and Vitis labrusca L. varieties in the maritime climate of Samsun in Turkey's Black Searegion. South African Journal of Enology and Viticulture 35(1): 90-102.

McMaster GS, Wilhelm WW (1997) Growing degree-days: one equation, two interpretations. Agriculture and Forest Meteorology 87: 291-300.

Mullins MG, Bouquet A, Williams E (2004) Biology of the grapevine. Cambridge University Press, London.

Nunes NAS, Leite AV, Castro CC (2016) Phenology, reproductive biology and growing degree days of the grapevine 'Isabel' (Vitis labrusca, Vitaceae) cultivated in northeastern Brazil. Brazilian Journal of Biology 76(4): 975-982.

Payero J (2017) Growing Degree-Day Calculator for the Southeast USA. Cooperative Extension, AC10, pp. 4.

Perry KB, Wehner TC, Johnson GL (1986) Comparison of 14 methods to determine heat unit requirements for cucumber harvest. Hortscience 21(3): 419-423.

Sağlam M, Boz Y, Kiracı MA, Aydın S (2009) Sofralık üzüm çeşitlerinin Trakya bölgesindeki değişik ekolojik koşullara uyumu. Türkiye 7. Bağcılık ve Teknolojileri Sempozyumu Cilt 2, Manisa, s. $129-138$.

Uzun Hİ (1997) Heat summation requirements of grape cultivars. Acta Horticulturae 441: 383-386.

Winkler AJ, Cook JA, Kliewer WM, Lider LA (1974) General viticulture: Second revised edition. University Of California Press, Berkeley, California.

Yalçın G, Demircan M, Ulupınar Y, Bulut E (2005) Klimatoloji-1. Devlet Meteoroloji İşleri Genel Müdürlüğü Yayınları. Yayın No: 2005/1, Ankara. 